Fecha de recepción: enero de 2019 Fecha de aceptación: marzo de 2019

Link para este artículo: https://dx.doi.org/10.14198/RHM2019.37.05

Puede citar este artículo como:

GONZÁLEZ LóPEZ, Tamara, «Actores y roles en el bautismo de socorro (Lugo, s. XVI-XIX)», Revista de

Historia Moderna. Anales de la Universidad de Alicante, n. 37 (2019), pp. 126-156, DOI: 10.14198/

RHM2019.37.05.

\title{
ACTORES Y ROLES EN EL BAUTISMO DE SOCORRO (LUGO, S. XVI-XIX) ${ }^{1}$
}

\author{
TAMARA GONZÁLEZ LÓPEZ \\ Universidade de Santiago de Compostela \\ tamara.gonzalez.lopez@usc.es \\ https://orcid.org/0000-0003-3778-1931
}

\section{Resumen}

El fallecimiento de un niño sin ser bautizado suponía privarlo de su entrada en la religión católica. Para evitarlo, el bautismo de socorro se convirtió en un recurso necesario y vital, normalmente administrado por mujeres que atendían el parto. La Iglesia, temiendo la suplantación de sus funciones, estableció ciertas normas que derivaron en una variación de los roles limitando la capacidad de actuación de las mujeres. El bautismo de socorro condicionaba el padrinazgo posterior del recién nacido y, por ende, la red social que se creaba a su alrededor.

Palabras clave: bautismo de socorro, bautizante, Iglesia, partera, padrinos, edad moderna, Galicia

Actors and roles in the urgent baptism (Lugo, XVIth-XIXth)

\section{Abstract}

The death of a child without being baptized supposed to deprive him of his entry into the Catholic religion. In order to avoid it, the urgent baptism became a necessary and vital resource which normally was done by women attending childbirth. The Church, which had fear of losing it functions, established some rules at baptism that resulted

1. Trabajo realizado en el marco del Proyecto de Investigación «El monte comunal en Galicia desde comienzos de la edad moderna a la actualidad: de soporte de un viejo complejo agrario a recurso medioambiental y patrimonio paisajístico» HAR2014-52667-R, financiado por la Agencia Estatal de Investigación y Fondos Feder de la Unión Europea. 
in a change in the roles, limiting woman acting capacity. Urgent baptism conditioned the subsequent godparenthood and, also, the created social network.

Keywords: urgent baptism, baptizer, Church, midwife, godparenthood, modern age, Galicia

Hasta la medicina moderna, el momento de dar a luz representaba un trance de gran tensión para las mujeres por el riesgo de muerte. La atención a la madre durante ese momento acostumbraba a estar en manos de otras mujeres, ya fuesen de la propia familia o vecinas con experiencia en partos. Dado que muchos alumbramientos eran complicados y ponían en riesgo la vida de la madre y/o el bebé, la rapidez y corrección a la hora de realizar un bautismo de socorro resultaba fundamental desde el punto de vista de la Iglesia, hasta el punto de que, si el niño o la niña sobrevivía, dicho bautismo podía marcar un fuerte lazo durante la vida del infante.

Para ilustrar los roles en los casos de bautismo de socorro, hemos escogido varias parroquias gallegas con perfiles distintos, pero todas pertenecientes a la diócesis de Lugo $^{2}$. Aunque hemos tenido en cuenta factores como la pertenencia jurisdiccional o el marco geográfico, la comparación que mayor interés ha suscitado es entre el mundo rural y urbano. Hemos tomado muestras iniciadas cada cincuenta años dentro de las posibilidades de cada libro parroquial, del tamaño de las parroquias y de sus ritmos demográficos. El marco temporal abarca desde el siglo XVI, cuando el Concilio de Trento impuso una nueva normativa sobre el bautismo, hasta finales del siglo XIX, lo que permite observar los cambios y permanencias a largo plazo.

2. Las parroquias utilizadas de muestra son Santa Baia de Aguada, San Lourenzo de Albeiros, San Salvador de Asma, San Pedro de Besteiros, Santa Baia de Bolaño, Santo Estevo de Cartelos, Santa María de Castroverde, Santa María de Cebreiro, San Pedro de Cellán de Calvos, Santiago de Cereixedo, Santa Mariña de Chantada, San Xoán da Cova, San Paio de Diomondi, San Miguel de Eiré, San Xián de Eiré, San Cristovo de Lóuzara, San Pedro de Lugo, San Paio de Muradelle, San Pedro de Noceda, Santa María de Nogueira de Miño, Santa María de San Lourenzo de Penamaior, San Vicente de Pino, San Nicolás de Portomarín, Santa Mariña de Pumarega, Santa María de Quinta de Lor, Santa María de Rao, Santa María de Régoa, San Martiño de Requeixo, San Salvador de Sarria, San Xián de Tor, San Xoán de Tor y San Martiño de Zanfoga 
Para la mejor contextualización de estos datos, se han utilizado tratados sobre la materia de la época, así como las obras normativas que afectaban a la citada diócesis.

El sistema familiar predominante en Lugo, de familias extensas, se sostenía en un sistema de transmisión patrilineal del patrimonio, en el que se priorizaba a un hijo sobre los demás, de modo que los otros tenían serias dificultades para establecerse por sí mismos y casarse; en consecuencia, allí se alcanzaban altas cotas de celibato en ambos sexos. Destacamos esta información porque significa que las mujeres daban a luz en casa de sus maridos y en ese espacio había un número importante de corresidentes que eran los primeros en atender a la parturienta. Aunque algunos autores han defendido el traslado de la mujer para dar a luz a la casa de sus padres, no se observa este comportamiento en la diócesis de Lugo, lo cual no obsta para que la madre $u$ otras mujeres de su familia se desplazasen a su nuevo domicilio para asistirla ${ }^{3}$.

\section{La normativa eclesiástica sobre el bautismo de socorro}

El bautismo de socorro o de necesidad era aquel en el que se echaba agua a un recién nacido que estaba sin bautizar y se consideraba que su vida estaba en peligro. La gran mayoría de bautismos de socorro se realizaba en el transcurso del propio parto, aunque también se produjeron casos en los que se administraba varias horas o días después. Es decir, si el niño mostraba signos de riesgo posteriormente, pero todavía no había sido conducido al templo parroquial para recibir el bautismo solemne.

Las importantes implicaciones que tenía el sacramento bautismal como rito de entrada en la comunidad de fieles motivaron que se estableciesen unas pautas en la normativa diocesana, tanto del bautismo solemne como del de socorro. La atención a este último partía de que no dejaba de ser una suplantación de las funciones propias y exclusivas del párroco y en su capacidad de control; de ahí que numerosas constituciones sinodales peninsulares de los siglos XIV y XV ya hiciesen especial énfasis en condenar su administración

3. TASSIN, 1998: 64. 
en el hogar, salvo que fuese de clara emergencia ${ }^{4}$. La diócesis de Lugo fue parca en textos sinodales, especialmente en la Edad Moderna, cuando solo contamos con tres obras del siglo XVII: don Alonso Gallo (1618), manuscrita, don Diego de Vela (1632) y don Matías de Moratinos de Santos (1669). No hubo, pues, una nueva normativa sinodal que afectase al bautismo desde el siglo XVII hasta el XX.

En las Constituciones del obispo Gallo, no se cita el bautismo de socorro más allá de reiterar la prohibición de que los párrocos bendijesen el agua en las casas de sus feligreses ${ }^{5}$.Por su parte, en las de Diego de Vela y Moratinos de Santos, el bautismo de socorro aparece reflejado de forma idéntica, evidenciando la continuidad tanto del método como sobre quién podía administrarse dicho sacramento ${ }^{6}$. En ambos se cita la obligación del párroco de bautizar conforme al Ritual Romano, obra cuya posesión se consideraba obligatoria y que, en la práctica, acostumbraba a estar ausente de las bibliotecas de los párrocos rurales ${ }^{7}$.

La normativa debía abordar dos espacios: el hogar, donde se administraba dicha agua de socorro, y la iglesia, a donde se debía llevar después al recién nacido. En el primero, se planteaba quiénes podían bautizar y, respecto al segundo, se establecía cuándo y cómo se bautizaba, así como quiénes apadrinaban.

La regulación de quién podía bautizar se debía a que la Iglesia era consciente de los riesgos de que el recién nacido falleciese sin ser bautizado y de la imposibilidad de los eclesiásticos de estar presentes en todos los partos. Además, dado que en determinadas áreas el bautismo en el hogar estaba extendido, erradicarlo súbitamente suponía confrontarse con la población y, en el caso gallego, por su hábitat disperso, resultaba imposible controlar que no se administrase en ningún parto ${ }^{8}$. Por ende, se permitió delegar dicha

4. García y García, 1981; 1984. Por ejemplo, en el Sínodo de Pedro Pacheco (Mondoñedo, 1534), en el de Diego de Muros (Tui, 1482) o en el de Diego de Avellaneda (Tui, 1528), entre otros.

5. Agradecemos al personal del Arquivo Diocesano de Lugo el préstamo desinteresado de la transcripción de las Constituciones de López Gallo.

6. VELA, 1632: 104-105. MORATINOS y SANTOS, 1675: 207-210.

7. PABLO V, 1614.

8. SÁNCHEZ DiEGO, 2018: 341. Diferentes constituciones sinodales pretridentinas de la península condenan el bautismo en el hogar, considerándolo una práctica extendida. 
función en las situaciones de riesgo y, para no perder el control sobre él, establecieron al menos tres medidas comunes a todas las diócesis: regularon la figura del bautizante a través del establecimiento de una jerarquía, otorgaron al párroco la potestad de decidir si el bautismo realizado había sido válido y, además, configuraron una herramienta preventiva dando la potestad a los párrocos de bautizar una segunda vez, en lo que denominaron bautismo subconditione ${ }^{9}$.

La jerarquía establecida de bautizantes mantenía la prioridad del párroco para administrar el sacramento si estaba presente, puesto que, aunque no se realizase en el templo, era competencia exclusiva de él. En su ausencia, debía tomar el relevo cualquier otro eclesiástico. La preferencia de los eclesiásticos es lógica dado que todos ellos debían poseer conocimientos sobre los sacramentos y su administración ${ }^{10}$. En los siguientes niveles de la jerarquía era donde se hallaba la incoherencia, puesto que, ante la falta de un eclesiástico, antecedían los hombres a las mujeres, aun cuando estas hubieran sido formadas específicamente para tal cometido por el cura ${ }^{11}$.

Resulta incoherente no solo porque los partos acostumbraban a ser atendidos por parientas o vecinas que, en consecuencia, adquirían un cierto conocimiento y experiencia para detectar los casos de peligro; además de tener una mayor probabilidad de estar presentes. Pero, sobre todo, porque las propias Constituciones Sinodales que relegaban a la mujer en los bautismos de socorro, obligaban a los párrocos a formar a las parteras o comadres en el método y procedimiento para bautizar en caso de peligro. Incluso, reservaban al rector parroquial la potestad de prohibir a estas mujeres ejercer su oficio basándose en su ignorancia sobre cristianar de urgencia $^{12}$.

9. El bautismo subconditione estaba concebido para los expósitos, puesto que no se podía aseverar que estuviesen bautizados, ni siquiera cuando traían una cédula que así lo afirmase.

10. BARRIO GOZALO, 22 (2002): 51. Entender los sacramentos y estar instruido en las ceremonias de la misa eran requisitos para ser ordenado presbítero.

11. BOROBIO, 43 (1996): 24-25. Se trata de un debate y una jerarquía heredados de la Edad Media.

12. Sin embargo, a los conocimientos en obstetricia que debían tener no se hizo mención alguna, puesto que la Iglesia no buscaba regularlo, solo añadir un requisito para acceder al oficio que les diese un cierto control. 
En lo tocante a la acción que discurría en la Iglesia, la normativa aludía explícitamente al tiempo que se dejaba transcurrir para llevar al templo parroquial al recién nacido. Para la generalidad de los niños, el plazo dado era de ocho días como máximo, pero para aquellos que habían sido bautizados de socorro se les permitía un plazo de quince días para que llevasen a la criatura a solemnizar la ceremonia. Se presuponía que la criatura estaba débil para sacarla del calor del hogar y llevarla al templo, por lo que se prefería optar por darles más tiempo; además, aunque falleciese, su alma no quedaría en el limbo por estar bautizada de socorro.

En el templo parroquial, el párroco debía interrogar al bautizante para averiguar si el bautismo había sido administrado correctamente. Esta indagación se debía a que el cura debía proceder de forma distinta en función de cómo lo valoraba, puesto que no podía rebautizar sistemáticamente a todos los niños si habían sido bautizados correctamente, porque recibir el agua «imprime carácter en el alma que siempre queda» ${ }^{13}$.Si el resultado del interrogatorio era satisfactorio para el cura, este procedía a suplir las ceremonias y exorcismos, que consistían en administrar el óleo y el crisma al neonato. La obligación de recibir esta segunda parte de la ceremonia requería que la criatura fuese llevada al templo, incluso cuando había sido el propio párroco quien había cristianado de emergencia a la criatura. Además, este acto era requisito indispensable para registrar a la criatura en el libro sacramental, por lo que no llevarlo comportaba su ausencia en los libros.

En este caso, quienes contraían parentesco espiritual con el bautizado y con sus padres y, por tanto, estaban sujetos a restricciones impuestas por el parentesco espiritual -en especial las matrimoniales como si fueran parientes sanguíneos-, eran el bautizante y quien hubiese ejercido como padrino en el hogar; mientras que aquellos que fuesen nombrados como padrinos al suplir las ceremonias no lo contraían, ya que no se emparentaba cuando no «hay bautismo, sino solo exorcismos y ceremonias» ${ }^{14}$. La única excepción

13. MANRIQUE DE LARA, 1994: VI. El rito del bautismo se componía de la administración de siete elementos. Al recibir agua de socorro, solo se recibía uno de ellos, razón por la que se debía completar.

14. Moratinos y SAnTOS, 1675: Lib. I, Tít. I. Según la teoría, el bautizante también contraía parentesco espiritual, aunque este fue frecuentemente relegado de la esfera de parentescos. 
eran los progenitores que, aunque echasen agua de socorro correctamente, no creaban parentesco espiritual ${ }^{15}$. Debido a la multiplicidad de parentescos espirituales que parecía contraerse en estos casos, las autoridades trataron de promover que fuesen padrinos los mismos que habían echado el agua de socorro. Sin embargo, en la normativa no había mención alguna a ello, por lo que se procedió de forma libre.

Si se consideraba que el bautismo no había sido administrado correctamente, el párroco bautizaba bajo condición de forma idéntica a cuando lo hacía solemnemente, salvo la fórmula que incluía la advertencia «si non es baptizatus, ego te baptizo...»/«si no estás bautizado, yo te bautizo... ${ }^{16}$. Al invalidarse el bautismo de socorro, los implicados no habían establecido relación espiritual alguna con el bautizado y sus padres.

Por tanto, al párroco se le presentaba la disyuntiva de validar el bautismo realizado, para lo cual se basaba en la corrección de la materia, forma e intención con la que se había administrado en el hogar. Estos elementos también debían ser los adecuados cuando se procedía de forma solemne, pero se presuponía que el párroco estaba bien formado en su administración, por lo que emplearía la materia correcta, la forma específica y tendría intención de bautizar. Formación que no tenía el resto de la población, por lo que era necesario supervisarlo.

Por materia se entiende el agua a usar. Las constituciones sinodales recogen la prohibición de mezclar el agua con otros elementos como flores, afirmando que «no sería bautismo el que con ella se hiziesse» porque sería agua artificial y no natural ${ }^{17}$. De forma semejante, se establecía la calidad del agua a emplear, que debía estar en forma fluida y no ser sólida como granizo o nieve ${ }^{18}$.

15. Alfani, 2009: 20. Fue un argumento usual en la Edad Media para obtener la separación, dado que los parientes espirituales no podían contraer matrimonio. PICCO, 2009: 205. Otras normativas, como el Ritual Parisien (1654) prohibieron a los padres bautizar de socorro.

16. Moratinos y SAnTOS, 1675: Lib. III, Tít. XIV, Const. III. Esta fórmula no era exclusiva para los bautismos de socorro, sino que su uso era obligatorio para bautizar a los expósitos por la ignorancia de que estuviesen bautizados y, si portaban cédula que así lo reseñase, de si había sido correcto.

17. VELA, 1632: Lib. I, Tít. I.

18. RODRÍGUEZ LuSITANO, 1596: 54-55. VEGA, 1602: 63v. 
El segundo elemento, la forma, hace referencia a dos cuestiones: la fórmula usada para bautizar y el método. La fórmula que se debía decir era «Ego te baptizo in nomine Patris, Filii, Spiritus Sancti», aunque sin la primera palabra seguía siendo igual de válida. La fórmula aparecía en latín en las constituciones sinodales, pero era lícito decirla en cualquier lengua mientras mantuviese el sentido; aspecto importante, dado que la lengua vehicular de la población no era ni el latín ni el castellano, sino el gallego ${ }^{19}$. De hecho, no hemos encontrado ningún bautismo que fuese invalidado por no emplear la fórmula en latín; aun así, no podemos desechar que, de la misma forma que la población llegaba a aprenderse las oraciones de corrido, no hiciesen lo mismo con la fórmula para bautizar y aquellos que se dedicaban profesionalmente a asistir partos, posiblemente, la aprendiesen también en latín.

Respecto al método, existían tres posibilidades: inmersión, aspersión e infusión, pero las circunstancias del bautismo de socorro propiciaban que se emplease la infusión ${ }^{20}$. En teoría, al emplear la infusión debía ser derramada el agua sobre la cabeza del bautizado por ser el «recipiente fundamental de la consciencia individual ${ }^{21}$; sin embargo, las constituciones sinodales especificaban que se podía echar «en parte principal del cuerpo en caso de necesidad $»^{22}$. Este dato apenas fue recogido en las partidas bautismales, aunque excepcionalmente hay testimonios como la alusión que hizo el párroco de Tuimil sobre el nacimiento de Andrés Gabriel (1756) «a quien baptizó de socorro labándole el pie Juan Pérez», al que califica de «hombre rústico» ${ }^{23}$. En esta ocasión debió ser tan evidente que se había procedido incorrectamente que, ya antes de ser llevado al templo, fue bautizado subconditione por otro clérigo.

19. Boullón Agrelo, 8 (2007): 19-20.

20. Carmona González y Saiz Puente, 4 (2009): 16-17. Desde el sector médico llegaron a plantear el bautismo intrauterino a través de jeringas para bautizar en los casos de pocas probabilidades de supervivencia de la madre como alternativa a las cesáreas en vida.

21. SÁNCHEZ DIEGO, 2018: 341.

22. MORATINOS Y SANTOS, 1675: Lib. I, Tít. I. La referencia a «parte principal» posiblemente se trate de un reflejo de los debates de la época sobre la localización del alma: cabeza o corazón, como se ve en FLORES DE LA FLOR, LXVI/2 (2014).

23. Archivo Central Diocesano de Lugo (en adelante ACDLu), Libro I de Bautismos de Santa María de Tuimil, 1716-1824: 86v. 
Finalmente, el tercer elemento era la intención de quien bautizaba, lo que no solo hacía referencia a la intención de bautizantes de otras confesiones, sino que los manuales citaban a ciertos sectores a los que niegan la presunta intención y, por tanto, el bautismo que realizasen no sería válido: los tachados de «locos» ${ }^{24}$. Además de la intención, entendida como la determinación para bautizar, también se analizaba la calidad de esta. El bautizante debía mostrarse firme y seguro al recitar la fórmula, en tanto que los titubeos podían invalidar un bautismo. Fue el caso de don Carlos de Froilán Pereira, cura propio de San Martín de Zanfoga, que al examinar a quien había bautizado de socorro a un bebé «hallé que titubeaba y no diçía bien la forma del bautismo y por eso le bolví a bautiçar subconditione» ${ }^{25}$.

Debemos recalcar la importancia que el sacramento bautismal tenía en la doctrina cristiana, pues no recibirlo suponía no haber eliminado la mácula que dejaba el pecado original y, en consecuencia, que el alma de la criatura permaneciese en el limbo al fallecer.

\section{El bautismo de socorro en la práctica: actores y validez}

La administración del bautismo correspondía al párroco y debía tener lugar en la iglesia parroquial, pues la normativa eclesiástica lucense especificaba la prohibición de bautizar a una criatura en otra iglesia o en ermitas ${ }^{26}$. No en vano, este sacramento suponía una fuente de ingresos, así como un método de control de la población, por lo que la Iglesia puso especial atención en él. Mayor control se puso, por tanto, en los bautismos de socorro, puesto que representaban la apropiación de una potestad que correspondía totalmente al párroco.

Este control, unido a la idea de que solo debía aplicarse en casos de peligro de muerte, parece ser la principal explicación de que solo el 1,75\% de las criaturas recibiesen agua de socorro ${ }^{27}$. Sin embargo, es preciso apuntar

24. RODRÍGUEZ LUSITANO, 1596: 56.

25. ACDLu, Libro I de Bautismos de San Martiño de Zanfoga, 1686-1756: 312.

26. Moratinos y SAnTOS, 1675: Lib. III, Tít. XIV, Const. II.

27. MinVIELLE, 2009: 301-302. No se observa la práctica hallada entre las élites de Burdeos por Minvielle en la que el bautismo de socorro fue empleado como medida preventiva para disponer de más días para organizar la celebración con la connivencia de los 
a otros factores que incidieron en que esta cifra no fuese mayor, ya que solo incluye a aquellos niños que sobrevivieron el tiempo suficiente para ser llevados a la iglesia a suplir las ceremonias, pues los párrocos lucenses no acostumbraron a anotar a aquellos que fallecían antes ${ }^{28}$. Dado que la Iglesia estableció quince días como plazo para llevar a bautizar a estos niños a la iglesia y la alta mortalidad de los neonatos en ese lapso, el número de bautizados de socorro que no fueron registrados por los párrocos tuvo que ser considerable ${ }^{29}$. Sin embargo, es posible que la proporción de ellos respecto al total de nacidos no se alterase en demasía, puesto que el número de niños fallecidos sin ningún tipo de bautismo sería igualmente importante. Desde luego, los plazos manejados por los padres son una variable fundamental para el cálculo, ya que cuanto más amplios fuesen, mayor probabilidad de infravalorar tanto los bautizados de socorro como las criaturas fallecidas en sus primeros días de vida.

Otra razón que puede llevar a la infravaloración del número de bautizados de socorro es la propia fuente, puesto que solo hay constancia de la administración de urgencia a través de la partida bautismal. A partir del siglo XVIII, su registro sigue un mismo modelo que induce a considerarlo como una anotación sistemática; sin embargo, con anterioridad, la brevedad de las partidas bautismales y la escasa atención a determinados detalles muestran un comportamiento totalmente opuesto. Pero, incluso en el siglo XVIII, la propia formación del párroco explica que, mientras unos se explayaban dando datos, otros finiquitasen la cuestión con un sucinto «recibió agua de socorro». En consecuencia, la cifra de bautizados de emergencia muestra una gran divergencia entre el siglo XVII y el siglo XIX, evidenciándose una clara tendencia al aumento del número de bautizados de socorro.

eclesiásticos. Sin embargo, no podemos desechar que fuese una práctica existente a espaldas del clero parroquial.

28. SAAVEDRA FERNÁNDEZ, 1 (1992): 84. En algunas parroquias sí fueron registrados estos niños, pero en ninguna de las parroquias aquí tomadas como objeto de estudio. Se ha cifrado en el 3\% los niños que fallecerían en esta situación.

29. Ibídem.: 92. Del total de párvulos fallecidos, el 27,4\% de ellos murió antes de cumplir los ocho días. 
Tabla 1. Evolución del número de bautismos de socorro

\begin{tabular}{|c|c|c|c|c|c|c|c|c|}
\hline & $\begin{array}{c}\text { Mdos. } \\
\text { s. XVI }\end{array}$ & $\begin{array}{c}\text { Tráns. } \\
\text { s. XVI- } \\
\text { XVII }\end{array}$ & $\begin{array}{c}\text { Mdos. } \\
\text { s. XVII }\end{array}$ & $\begin{array}{c}\text { Tráns. } \\
\text { s. XVII- } \\
\text { XVIII }\end{array}$ & $\begin{array}{c}\text { Mdos. } \\
\text { s. XVIII }\end{array}$ & $\begin{array}{c}\text { Tráns. } \\
\text { s. XVIII- } \\
\text { XIX }\end{array}$ & $\begin{array}{c}\text { Mdos. } \\
\text { s. XIX }\end{array}$ & $\begin{array}{c}\text { Tráns. } \\
\text { s. XIX- } \\
\text { XX }\end{array}$ \\
\hline $\begin{array}{c}\text { Bautizados } \\
\text { de socorro }\end{array}$ & 5 & 5 & 21 & 34 & 58 & 92 & 65 & 25 \\
\hline & $1,63 \%$ & $0,48 \%$ & $1,10 \%$ & $1,21 \%$ & $2,05 \%$ & $3,11 \%$ & $2,17 \%$ & $0,92 \%$ \\
\hline $\begin{array}{c}\text { Total } \\
\text { Bautizados }\end{array}$ & 306 & 1035 & 1901 & 2819 & 2827 & 3027 & 3047 & 2616 \\
\hline
\end{tabular}

Fuente: Libros bautismales de 36 parroquias lucenses.

En el siglo XVI y en el XVII, los amplios plazos manejados por los progenitores y la escritura esquemática de las partidas bautismales implicaron el registro de un escaso número de niños que recibieron agua de socorro: entre el $0,48-1,21 \%^{30}$. A partir del siglo XVIII, se empezaron a reducir los días que los padres dejaban transcurrir sin llevar al templo parroquial a bautizar a sus hijos; paralelamente, aumentó la calidad e información que se incluía en las partidas bautismales, por lo que se percibe un incremento de esta práctica, llegando a su máximo a inicios del siglo XIX (3,11\%). Junto a ello, la creciente consideración de la infancia como etapa diferenciada que se estaba expandiendo desde los núcleos urbanos conllevaba una mayor preocupación por los niños, lo cual, unido a una predicación religiosa más efectiva de las implicaciones de la muerte de los neonatos sin cristianar, llevaría a los presentes en el parto a realizar un bautismo de socorro ante la mínima duda de supervivencia del recién nacido ${ }^{31}$.

La tendencia al alza de los bautismos de emergencia se rompió a lo largo del siglo XIX, reduciéndose al 0,92\% a finales de siglo. Como causas se pueden

30. Cifras que distan ampliamente del 5\% calculado por BASILICO, 11/1 (2010): 14, para la segunda mitad del siglo XVII en Teramo (Italia). Por el contrario, se aproxima más a los resultados dados por MARTínEZ RODRÍGUEZ, 1 (1992): 48 para la ciudad de Santiago de Compostela: 0,50-1,26\%; aunque estos solo serían los bautizados de socorro que habían fallecido.

31. ARIÈs, 1987: 186-187. Sitúa en el siglo XVII el despertar de una conciencia diferenciadora de la infancia, así como de la preocupación de la familia por el bienestar de los hijos. 
apuntar las mejoras médicas, que significaron un menor riesgo de muerte por causas derivadas del propio parto del neonato y, por ende, una menor necesidad de recurrir a este bautismo ${ }^{32}$. Sin embargo, fue más determinante que, en el siglo XIX, se extendiese en la diócesis de Lugo la práctica de bautizar dentro de las primeras cuarenta y ocho horas de vida frente a los cuatro o cinco días que se esperaba antes, lo que significa que un menor volumen de niños fallecieron con bautismo de socorro sin ser anotados e, igualmente, que el bautismo solemne substituyó al de socorro. Es decir, salvo casos en los que se previese una muerte inmediata, en lugar de bautizar de socorro, se acudiría con más apuro al templo parroquial.

Tampoco se puede obviar el impacto del cambio que se estaba produciendo en el clero lucense. Las distintas medidas del obispado de esta diócesis para mejorar la calidad formativa y el modo de vida de sus párrocos rurales fueron cuajando y se hicieron visibles a lo largo del siglo XIX ${ }^{33}$. Estas implicaban una aplicación estricta de la doctrina y la normativa que, posiblemente, derivó en un control férreo de aquellas acciones que eran potestad de los párrocos como la administración del bautismo. De hecho, como veremos a continuación, este férreo control derivó en un examen más minucioso de la forma en que había sido administrado el de socorro.

La mejora de la formación de los párrocos repercutía a su vez en el conocimiento de la doctrina que tenía la población. En ese sentido, parece imperar antes del siglo XVIII un total desconocimiento de las implicaciones del fallecimiento de un recién nacido sin cristianar. A ello apuntan los laxos plazos de bautismo que se manejaban en la diócesis de Lugo hasta el siglo XVIII y así lo denunciaba en el siglo XV el obispo de la vecina diócesis de Ourense, que afirmaba que algunos progenitores «dexan de baptizar a sus hijos por tiempo de un mes y aun cerca de un año» ${ }^{34}$. Sin embargo, parece que sí existía conciencia de ello cuando el parto se había complicado o la criatura nacía con pocas señales de vida: a finales de 1580, el capellán del monasterio de San Salvador de Asma (Chantada) anota en la partida de Pedro

32. SOBRADO CORREA, 2001: 360.

33. GONZÁLEZ LOPO, 2008: 158-159.

34. MANRIQUE DE LARA, 1994: XIV. 
que «en su casa por temor de muerte la abía exemplado el dho Gregorio de Lobelle» ${ }^{35}$.

Al comparar el volumen y el contexto de los bautismos de socorro en el siglo XIX entre la diócesis de Lugo y otras áreas, constatamos la importancia de ambos factores: el tiempo que mediaba entre nacimiento y bautismo, así como el control y la formación de los párrocos. En Francia, el número de niños que recibían agua de socorro fue en aumento en la segunda mitad del siglo XIX, como consecuencia de la nueva tendencia a dejar pasar varios días entre nacimiento y bautismo; pero, también, por la mayor permisividad del clero a los denominados «bautismos privados», que consistían en bautizar en el hogar como si fuese un bautismo de socorro, pero sin necesidad real, con el objetivo de dilatar la recepción del bautismo solemne y disponer de tiempo para organizar una ceremonia acorde al nivel social ${ }^{36}$.

Atendiendo ya a quiénes realizaron bautismos de socorro, vemos que la jerarquía de la que hablábamos se respetó en parte: el 43,6\% los hizo un hombre -excluyendo como tales a los clérigos- y solo el $26,2 \%$ una mujer. Junto a ellos, contabilizamos un $17,0 \%$ de casos en los que las fuentes no especifican quien echó el agua de socorro y un 13,1\% de clérigos. La baja participación de los eclesiásticos no se debió a un reducido número de ellos -de media había 1,61 por parroquia ${ }^{37}$-, sino más bien a que la concentración de partos en determinadas épocas y el hábitat disperso imposibilitarían al cura rector estar presente en todos ellos ${ }^{38}$. Además, en tanto el parto era asimilado como nacimiento carnal y vinculado al pecado y la impureza, no serían llamados salvo en caso de extrema necesidad.

Ahora bien, estas cifras esconden una diferencia temporal de la participación de cada sexo como bautizantes. Como se puede ver en la tabla 2, los

35. ACDLu, Libro I de Bautismos y Matrimonios de San Salvador de Asma, 1567-1633: 16. En las fuentes más antiguas, se utilizaba el término exemprar/enxembrar/enxemprar para referirse a echar agua de socorro; relacionado con el actual vocablo gallego enxebre que significa «sin nada más, sin mezcla», por lo que su empleo en el bautismo de socorro estaría causado por la recepción en él de solo uno de los siete elementos de los que se componía un bautismo. Aún en 1886, aparece recogido en un romance popular de tradición oral en Antonio de la IGLESIA, 1886: 113.

36. GOURDON, GEORGES y LABEJOF, 2004: 148-151.

37. Rey CASTELAO, 2002: 125.

38. SAAVEDRA, 62 (1992): 179-180.

Revista de Historia Moderna, n. 37 (2019) (pp. 126-156) | ISSN-e: 1989-9823 | ISSN: 0212-5862 
eclesiásticos tuvieron un papel importante en la segunda mitad del siglo XVI, pero pronto fueron sustituidos en dicha función. En estos primeros siglos esa ausencia de los fallecidos sin solemnizar el bautismo era más acuciante y, probablemente, el protagonismo de los eclesiásticos se debió a que solo anotasen aquellos en los que ellos mismos habían sido partícipes.

Tabla 2. Sexo de los bautizantes de socorro (s. XVI-XX)

\begin{tabular}{|c|c|c|c|c|c|c|c|c|}
\hline & $\begin{array}{c}\text { Mdos. } \\
\text { s. XVI }\end{array}$ & $\begin{array}{c}\text { Tráns. } \\
\text { s. XVI-XVII }\end{array}$ & $\begin{array}{c}\text { Mdos. } \\
\text { s. XVII }\end{array}$ & $\begin{array}{c}\text { Tráns. } \\
\text { s. XVII- } \\
\text { XVIII }\end{array}$ & $\begin{array}{c}\text { Mdos. } \\
\text { s. XVIII }\end{array}$ & $\begin{array}{c}\text { Tráns. } \\
\text { s. XVII- } \\
\text { XIX }\end{array}$ & $\begin{array}{c}\text { Mdos. } \\
\text { s. XIX }\end{array}$ & $\begin{array}{c}\text { Tráns. } \\
\text { s. XIX- } \\
\text { XX }\end{array}$ \\
\hline Mujer & - & 1 & - & 3 & 1 & 21 & 40 & 14 \\
\hline & - & $20 \%$ & - & $9 \%$ & $2 \%$ & $23 \%$ & $62 \%$ & $56 \%$ \\
\hline Hombre & 2 & 1 & 8 & 12 & 35 & 55 & 15 & 5 \\
\hline & $40 \%$ & $20 \%$ & $38 \%$ & $35 \%$ & $60 \%$ & $60 \%$ & $23 \%$ & $20 \%$ \\
\hline Eclesiástico & 3 & 2 & 5 & 6 & 12 & 9 & 2 & 1 \\
\hline & $60 \%$ & $40 \%$ & $24 \%$ & $18 \%$ & $21 \%$ & $10 \%$ & $3 \%$ & $4 \%$ \\
\hline Desconocido & - & 1 & 8 & 13 & 10 & 7 & 8 & 5 \\
\hline & - & $20 \%$ & $38 \%$ & $38 \%$ & $17 \%$ & $8 \%$ & $12 \%$ & $20 \%$ \\
\hline Total & 5 & 5 & 21 & 34 & 58 & 92 & 65 & 25 \\
\hline
\end{tabular}

Fuente: Libros bautismales de 36 parroquias lucenses.

Además de la continua pérdida de protagonismo de los eclesiásticos en esta labor, se observa un fuerte predominio de los hombres. A pesar de la parquedad de las partidas bautismales, los datos muestran que fueron el grupo más numeroso desde mediados del siglo XVI hasta inicios del XIX. La mejoría en los datos proporcionados por las partidas a lo largo del siglo XVIII reducen el desconocimiento de las circunstancias de los bautismos y, a su vez, evidencian que echar agua de socorro era un rol eminentemente masculino: más de la mitad fueron administrados por hombres laicos. Especialmente destacable es el contraste de mediados del siglo XVIII, cuando solo una mujer bautizó frente a más de treinta hombres; contraste que se ve favorecido por desconocer el sexo del bautizante en solo diez casos.

Sin embargo, esta situación comienza a revertirse al recuperar la mujer tanto el rol de bautizante como el espacio en el parto, que habían sido suplantados y mediatizados por el hombre. Se podría llegar a considerar que hubo dos fases de este proceso: una primera fase tendría lugar en la segunda mitad 
del siglo XVIII y en ella las mujeres substituirían a los eclesiásticos en la labor de bautizar en casa. En esto jugarían dos factores importantes: por un lado, las medidas impulsadas desde la sede episcopal lucense, orientadas a la adquisición, por parte del clero parroquial, de pautas de vida conformes a su condición de eclesiásticos y que habrían supuesto la última estocada para acabar con su presencia en los partos, al entenderse estos como una ocasión de sociabilidad profana ${ }^{39}$.

Por otro lado, no puede ser casual que el incremento del número de mujeres bautizando se produjese en el mismo marco cronológico que la reincorporación de las parteras al grupo de profesionales que debían pasar un examen ante el Protomedicato para ejercer ${ }^{40}$. Por tanto, las comadronas recuperaban parte de su prestigio, ya que al tener que pasar un examen no podían ser acusadas de ignorancia; esto no significó que el cuerpo de médicos las aceptase, pues tanto comadronas como parteras siguieron siendo objeto de sus más feroces críticas ${ }^{41}$. Ahora bien, la idea que se transmitía a la población en general era que una institución respaldaba a estas mujeres y sus prácticas, lo que unido al conocimiento y experiencia del parto por su propia condición de mujer, creaba en ellas un aura de cierto prestigio. Sin embargo, dudamos que esta idea llegase a las áreas rurales lucenses y, más bien, debemos apuntar a la mejor disciplina de los párrocos que serían más estrictos a la hora de prohibir a una mujer ejercer de partera si no la consideraba capacitada. Así, de una $\mathrm{u}$ otra forma, la autoridad de las mujeres para administrar un bautismo de socorro se reforzó, con el consecuente aumento de su presencia en dicho rol.

La segunda fase de este proceso de reversión se centraría en la primera mitad del siglo XIX y, en esta ocasión, las mujeres recuperarían el espacio que hasta el momento ocupaban los hombres. En ello pudo afectar la nueva consideración sobre la privacidad familiar que se estaba extendiendo desde los ámbitos burgueses; así, el parto deja de ser una convocatoria social para

\footnotetext{
39. Dubert GARCía, 1996: 381.

40. SUÁREZ ÁlVAREZ, 2014: 42-43.

41. ARENA, 2014: 80-82. La medicalización del parto llevó parejo un cuestionamiento de las prácticas relativas al parto y a la maternidad en toda Europa. La pésima reputación de las parteras estaba incrustada en la mentalidad popular e, incluso, relatos ajenos a las ciencias médicas las mostraban como perversas e interesadas. Como muestra el relato sobre el nacimiento de sor Margarita en MORTE ACín, 2018: 967-968.
} 
acompañar a los padres en el nacimiento y pasa a ser un suceso totalmente familiar, al que únicamente se deja acceso a otras mujeres con experiencia para tratar de evitar la muerte de la madre o el neonato.

Esta nueva perspectiva no implicaba la desobediencia a la jerarquía establecida por la Iglesia para la administración de un bautismo de socorro, sino que el espacio del parto se feminizó. En 1813, el párroco de Esmoriz dejó escrito que Dominga Vázquez, "por suponerlo [al recién nacido] con pocas o ninguna esperanzas de vida, baptizó por no haver allí hombre alguno $»^{42}$. Por tanto, debemos apuntar como principal hipótesis del auge del rol femenino la separación de los hombres de dicho espacio.

Analizando las cifras totales, se observa una baja proporción (16\%) de bautismos rechazados. Por razones obvias, todos los administrados por eclesiásticos fueron considerados válidos, por lo que el párroco solo tuvo que suplir las ceremonias. Entre los hombres y las mujeres fueron los primeros los que consiguieron una mayor tasa de aceptación: $89 \%$ y $80 \%$, respectivamente. La menor tasa de aceptación se encuentra entre aquellos cuya identidad desconocemos (65\%). Ante ello, debemos considerar la posibilidad de que el párroco entendiese correctamente las consecuencias de ello y, por tanto, no anotase la identidad de estos dado que no había implicación alguna en el parentesco espiritual. Sin embargo, la advertencia del parentesco espiritual contraído que realiza el párroco a los padrinos en las ceremonias en las que admitía el bautismo realizado, nos induce a considerar lo contrario.

En el plano temporal, los bautismos correctos fueron en aumento desde inicios del siglo XVIII, cuando uno de cada siete era rechazado. Así, a inicios del siglo XIX, la práctica totalidad de ellos fueron considerados válidos por el cura: únicamente seis invalidados de casi un centenar. Esta tendencia se rompió a lo largo del siglo XIX y se llegó al final del mismo rechazando dos de cinco de los bautizos hechos por un hombre y, en el caso de las mujeres, cuatro de catorce. La validez de los bautismos se situaba, por tanto, sobre el 60\% cuando, un siglo antes era del 93\%. La mayor atención de los párrocos al sacramento derivada de su mejor formación repercutió directamente en los bautismos al provocar que fuesen más minuciosos en sus exámenes y prefiriesen bautizar subconditione ante la mínima duda.

42. ACDLu, Libro III de Bautismos de San Xián de Esmoriz, 1804-1852: 7. 
La negativa del párroco no siempre derivó de haber dicho mal las palabras o haber echado el agua en indebida forma, sino que encontramos otros motivos como bautizar dos personas simultáneamente, hacerlo antes de tiempo o, simplemente, por «la duda prudente» del párroco que prefirió asegurarse $e^{43}$. Los párrocos apenas se explayaron en justificar su decisión y, por tanto, son excepciones los testimonios como el aportado por don Francisco de Arce, cura de la parroquia de Vilabade, quien bautiza subconditione a una niña por haberse empleado "palabras dudossas» ${ }^{44}$; o el del párroco de los beneficios de Tor, quien rechazó el bautismo realizado por María de Losada «por esta haverme dicho la aceleración y turbación con que lo havía hecho ${ }^{45}$. Sí fueron algo más minuciosos al dejar constancia del protocolo seguido en la averiguación: «examine antes de la forma o palabras que dixo al tiempo de echar sobre la cabeza el agua i de la intención i hallé que avía sido dho bauptismo con todos substanciales requisitos ${ }^{46}$.

En definitiva, las propias circunstancias del parto o de los progenitores fueron las principales causas que determinaron que fuese un varón o una mujer quien bautizase de necesidad. Podemos decir, pues, que tras unos años de transición en los que tanto hombres como mujeres realizaban bautismos de necesidad, a partir de la década de 1850, resulta infrecuente encontrar un varón realizando tal labor y, más aún, a un eclesiástico. La mujer llevó a cabo una recuperación del espacio que tradicionalmente había ocupado y de la que el varón se había agenciado la parte más visible y agradecida: salvar a la criatura de una muerte no cristiana.

\section{Los profesionales sanitarios y el bautismo de socorro}

Analizar el papel de los profesionales sanitarios en el bautismo de socorro en un área rural y con un hábitat disperso resulta arduo e infructuoso. Además, se agrava en el sector femenino cuya condición de partera o comadrona

43. ACDLu, Libro II de Bautismos, Matrimonios y Defunciones de Santa María de San Lourenzo de Penamaior, 1674-1763.

44. ACDLu, Libro I de Bautismos de Santa Baia de Bolaño, Santiago de Castroverde y Santa María de Vilabade, 1717-1782: 64.

45. ACDLu, Libro I de Bautismos de San Xoán de Tor, 1710-1849: 26v.

46. ACDLu, Libro I de Bautismos de San Vicente do Pino, 1724-1822: 5. 
acostumbró a ser omitida, al contrario que en los hombres. De hecho, las menciones al desempeño de dicha actividad fueron excepcionales y, normalmente, a través de la omisión de sus nombres: en la partida de Manuel (1890), el párroco anota «que informado de la partera nada tuve que dudar ${ }^{47}$.

Dado que estamos hablando de una situación que tenía lugar en el 2\% de los partos y de los que no tenemos más datos sobre quién estaba presente que la propia referencia del párroco, la información sobre quién y cómo era asistida la mujer en el parto es escasa. En consecuencia, no podemos afirmar a ciencia cierta que los bautizantes de socorro, especialmente las mujeres, se dedicasen profesionalmente a la obstetricia y, por extensión, no podemos saber si la jerarquía impuesta por la Iglesia era ignorada en beneficio de asegurar la calidad del bautismo de socorro.

El incremento de manuales sobre el «arte de partear» que tuvo lugar a mediados del siglo XVIII, como consecuencia de que las comadronas debiesen pasar el examen del Protomedicato, supuso la inclusión en estos textos científicos de un aspecto religioso ${ }^{48}$. Se alargaba, por tanto, la sombra de la Iglesia sobre estas mujeres, pues se trataba de la misma normativa que había sometido a las parteras al control del párroco. Ahora bien, en un territorio tan fragmentado parroquialmente como el del interior gallego y en el que algunas feligresías no llegaban a superar los veinte vecinos, el control efectivo de los curas sería reducido, ya que las parteras que se dedicasen a ello trascenderían el marco parroquial sin dificultad alguna ${ }^{49}$. Por su parte, las comadronas parece que fueron un sector exiguo, por no decir nulo. Incluso, podemos afirmar que, exceptuando partos en los que ya se preveían dificultades, se prefería recurrir a vecinas o familiares que, sin llegar a dedicarse

47. ACDLu, Libro III de Bautismos de San Xoán da Cova, 1852-1896: 121.

48. CARmona GonZÁlez y SaIz Puente, 4 (2009): 17-18. Aunque se impuso la obligación del examen en 1750, no fue hasta el manual de Gárate y Casabona de 1756 que se incluyó lo relativo al bautismo de socorro. La obra promovida por el Protomedicato para formar a las parteras, MEDINA, 1785, no aludía en ningún momento al bautismo de socorro.

49. REY CASTELAO, 2002: 97-98. El tamaño medio de la parroquia lucense se situaba en $6,46 \mathrm{~km}^{2}$, cifra dentro de la que hay importantes oscilaciones que van entre los 3,7 $\mathrm{km}^{2}$ de las parroquias más pequeñas a los $18,20 \mathrm{~km}^{2}$ de las parroquias situadas en las montañas del Courel. 
profesionalmente a ello, tenían una amplia experiencia en atender partos ${ }^{50}$. Los procesos de averiguaciones de partidas de bautismo dan fe de la asistencia de vecinas que aparecen reflejadas habitualmente en las declaraciones de testigos, como Manuela Valcárcel que declaró que fue llamada «para asistir a Antonia Monteagudo, mujer de Francisco de Macía, su cuñado $»^{51}$. La encuesta realizada para el Ateneo de Madrid en 1901, pese a referirse únicamente al final del período que aquí tratamos, nos proporciona una visión de esta falta de parteras con preparación académica. Las respuestas que se reciben de toda Galicia tienen el mismo esquema: el parto lo atienden «mujeres prácticas, sin título de comadronas que no existen en el país» y solo se llama a los médicos cuando hay problemas ${ }^{52}$.

Por el contrario, en las parroquias urbanas sí se puede detectar una mayor presencia de parteras. Es lógico, pues, que las mujeres que se ganaron la vida como tal tuviesen su radio de acción en las áreas más populosas, donde podían acudir a varios partos semanales sin tener que desplazarse continuamente como acaecería de desempeñar dicha labor en el área rural. Ayudó a ello que las ciudades gallegas no regulasen el acceso a esta profesión ${ }^{53}$.

Tanto es así, que las dos únicas mujeres de las que podemos sospechar que son parteras de profesión las encontramos en dos de las villas estudiadas: Doña Dolores Ojea, cuyo campo de acción se enmarca en el área de Chantada, y Josefa Baloira, en la villa de Monforte. Ambas aparecen en varios casos separados temporalmente por más de un año y sin que se pueda hallar ningún vínculo familiar con los neonatos. Además, Doña Dolores Ojea es la bautizante de socorro en dos de los tres partos gemelares que tuvieron lugar a finales del siglo XIX en Chantada; su presencia en estos partos cuya dificultad se podía prever nos induce a considerar que estaba preparada para atenderlos o, al menos, eso se le suponía ${ }^{54}$.

50. SAGE-PRANCHÈRE, 2007: 505. No se puede desechar que las parteras y comadronas no ejerciesen en estas áreas rurales por el propio rechazo de la comunidad por la condición foránea de estas.

51. Archivo Histórico Diocesano de Lugo (en adelante AHDLu), Sección Civil, Arciprestazgo de Sarria, Mazo 17 (1798-1805).

52. GONZÁlez REBOREdO Y MARIÑo FERRO, 1990: 35.

53. RiAL GARCÍA, 2009: 25.

54. Todo apunta a que el aprendizaje de Dolores estaría vinculado con la familia al ser nieta e hija de cirujanos: don Pedro Ojea y don Ramón Ojea Taboada, respectivamente. 
El factor urbano también se hace visible en lo tocante a los cirujanos, pues únicamente en las villas aparecen cirujanos que bautizan de socorro y, con anterioridad, barberos ${ }^{55}$. Por ejemplo, en 1592, en San Vicente do Pino, el párroco anota en la partida de un niño llamado Domingo que «havíale bautizado Lope de San Martiño, barbero» ${ }^{56}$. Más ilustrativo es el relato que Francisco Macía hizo del nacimiento de su hijo Antonio (1776):por los «muy graves dolores de parto» que padeció su esposa, llamaron a don Benito García Capón, cirujano, «que la asistió toda la noche con otras varias jentes y comadres y en la mañana del día veinte y seis dio a luz un niño que por parecerle al cirujano venía amortezido, le echó agua de socorro, por lo qual y otros fomentos fue bolviendo, mamó y exerció otras funciones vitales $»^{57}$.

No significa esto que los cirujanos estuviesen ausentes de las áreas rurales, sino que su participación en los partos y, por ende, en los bautismos de socorro, se circunscribió exclusivamente a los casos de mayor riesgo y en familias que pudieran afrontar el pago, que serían las menos. Así, contamos con excepciones como la ocurrida en noviembre de 1812, cuando el cirujano don José Martínez, vecino de Villasante, bautiza de socorro a una niña en San Xoán de Tor, ambas localidades de perfil rural ${ }^{58}$.

En suma, la intervención de los profesionales sanitarios se redujo por los avances médicos que aumentaron la seguridad en el parto y lo medicalizaron; pero, sobre todo, porque se sustituyó el bautismo de socorro por un rápido bautismo solemne en la iglesia parroquial.

Este último, estudiante entre 1829-1832 del Real Colegio de Medicina y Cirugía San Carlos: Archivo Histórico Nacional, Universidades, 1233, Exp.146. Podemos aseverar que no bautizó de socorro por acompañar a su padre quien, en 1868, hizo testamento con más de sesenta años (Arquivo Histórico Provincial de Lugo, Protocolos Notariales, José Vázquez Lorenzo, Ayto. Carballedo, 1868, Leg. 04836, ff. 225 y ss.); mientras que los bautismos referidos fueron en 1897-1901.

55. SAAVEDRA FERNÁNDEZ, 1994: 179. Las funciones del cirujano también incluían realizar cesáreas postmortem para extraer al niño y bautizarlo. Atendiendo al 2,5-8\% de mortalidad materna que se apunta en REY CASTELAO y RIAL GARCíA, 2010: 55-56, no se debe considerar que la presencia de los cirujanos en los partos fue menor.

56. ACDLu, Libro I de Bautismos, Matrimonios y Defunciones de San Vicente do Pino, 15591631: 61v.

57. AHDLu, Sección Civil, Sección Civil, Arciprestazgo de Sarria, Mazo 15 (1770-1792). 58. ACDLu, Libro I de Bautismos de San Xoán de Tor, 1710-1849: 67v. 


\section{El posterior padrinazgo}

La figura del padrino, pese a no establecer ningún vínculo legal, resultaba indispensable para bautizar. La elección de una persona como padrino representaba una honra para el escogido, pues se creaba un lazo de índole religiosa que trascendía al plano social y que duraba toda la vida ${ }^{59}$. Era un reconocimiento que proporcionaba prestigio dentro de la comunidad al ser necesaria para tal elección tener una buena reputación, así como la capacidad de educar en los principios religiosos básicos ${ }^{60}$.

El parentesco espiritual que se establecía entre padrinos y ahijados también se creaba al echar agua a una criatura, razón por la que en numerosas partidas no se menciona explícitamente a los padrinos por considerar que los bautizantes se convertían en ello automáticamente ${ }^{61}$. Como ya hemos apuntado, según las constituciones sinodales, en estas situaciones solo se creaba parentesco espiritual con quien administraba el agua de socorro y no con quien hacía de padrino en la ceremonia posterior; concepto sobre el que las fuentes muestran una extendida ignorancia ${ }^{62}$.

En teoría, en el bautismo de necesidad se nombraban padrinos, que debían ser los que repitiesen después, sobre todo si el bautismo se consideraba válido. Esto fue respetado en general, aunque contamos con excepciones puntuales en las que se cambió a los padrinos: en 1659, Inés de Armada hizo de madrina de su sobrino en casa, pero fue Catalina Vilela quien ejerció como tal en la pila bautismal. Sin embargo, solo las fuentes más antiguas aluden a la presencia de padrinos en el bautismo efectuado en el hogar, por lo que debemos considerar que, o bien se asimiló la figura del bautizante de socorro con el padrino, o bien se abandonó el nombramiento de padrinos en esos casos de urgencia.

59. FinE, 105-106: 1987. Defiende que la cultura popular hizo que el vínculo trascendiese la muerte, en tanto padrinos e ahijados fallecidos protegían el alma del otro en el Más Allá.

60. ALFANI, 2009: 89.

61. SAAVEDRA FernándeZ, 1 (1992): 33. Fueron múltiples los párrocos que dejaban la partida inconclusa si fallecía el bautizado, por lo que es otra razón por la pudieron no ser registrados los padrinos.

62. MORATINOS y SANTOS, 1675: Lib. I, Tít. I. 
Todo parece apuntar a ambas cuestiones, ya que la propia Iglesia se pronunció tratando de imponer que los bautizantes de socorro fuesen designados como padrinos en la ceremonia posterior, asimilándolos y, al mismo tiempo, esto evidencia que no había padrinos en el bautismo de urgencia, salvo excepciones. Así lo dejaba registrado el visitador general en 1826: «cuando se suplen las ceremonias del bautismo asistan padrinos y pudiendo ser el mismo ó la misma que le bautizó en caso de necesidad, anotándolo en la partida» ${ }^{63}$. Esta advertencia, que se tomaba como obligación, tenía una doble función: por un lado, evitar la multiplicidad de parentescos espirituales dado que se fusionaba en la misma persona el parentesco creado por bautizar y el creado por apadrinar, que de otra forma correspondería a dos personas distintas. Por otro lado, al obligar a que el bautizante de socorro acudiese a la ceremonia que solemnizaba el bautismo, se garantizaba poder interrogarlo y evitar administrarlo subconditione sobre uno correcto o solo administrar los óleos cuando el de socorro era inválido.

En efecto, el 46,60\% de aquellos que echaron agua de socorro, ejercieron con posterioridad como padrinos; cifra que podría ser superior si consideramos que se produjo dicha asimilación entre bautizante y padrino en los niños cuyos padrinos no constan de forma explícita, lo que supondría aumentar el $7,77 \%$. En ciertas parroquias, no se anotó explícitamente la doble condición de bautizante y padrino, induciéndonos a la duda de si existía dicha doble condición o si, por el contrario, no se habían designado padrinos. La advertencia a quien contraía el parentesco espiritual no diluye la duda, en tanto quien bautizaba también contraía dicho parentesco, aunque este vínculo fuese normalmente olvidado. Además, contribuyó a esta asimilación el alto índice de validez de los bautismos, que colocaba a un escaso 16\% de progenitores en el dilema de mantener al mismo bautizante como padrino, en tanto el bautismo no era válido $\mathrm{y}$, por consiguiente, no se había creado parentesco espiritual con él.

De igual forma, sucede en la quinta parte de los casos, en los que desconocíamos la identidad del bautizante de socorro que, por tanto, podía ser quien apadrinase. En total, solo en el $25 \%$ de los casos no se produjo una

63. ACDLu, Libro II de Bautismos de San Xián de Ourol, Santa Cruz de Grolos y San Miguel de Vilarmao, 1783-1844: 108v. 
correspondencia entre bautizante y padrino, casos en los que se ocultan multiplicidad de situaciones por las que los progenitores no mantuvieron a los bautizantes como padrinos. Se trató, principalmente, de los casos en los que el bautizante era un ajeno a la familia que, por la jerarquía establecida por la Iglesia, tenía prioridad como bautizante: eclesiásticos, cirujanos y todos los casos en los que sospechamos que la bautizante ejercía el oficio de partera.

Aun así, no se puede descartar que ese $25 \%$ se correspondiese con una práctica social diferente, puesto que podría considerarse una estrategia de ampliación de los parientes espirituales que, desde el Concilio de Trento, se habían reducido ${ }^{64}$. En la teoría, la población creaba parentesco espiritual con el bautizante, al tiempo que podían establecer una relación de padrinazgo con otra persona, expandiendo más sus lazos sociales. Sin embargo, en la práctica, no estaba asumida la normativa por la que aquellos que ejercían de padrinos solo al suplir la ceremonia no contraían parentesco espiritual. En consecuencia, los bautizantes acostumbran a ser los sujetos olvidados al tratar las alianzas derivadas del parentesco espiritual, al centrarse el protagonismo únicamente en el padrinazgo, con quien la población y los estratos más bajos de la Iglesia creían que se establecía el parentesco. ${ }^{65}$. No obstante, aun reconociendo el mayor valor que tenían los padrinos en las redes sociales, no podemos desechar como inservible el parentesco espiritual creado con los bautizantes que, salvo en los bautizos de socorro, eran siempre eclesiásticos. Solo encontramos un caso en el que el párroco diferenció entre ambos anotando que

fueron sus padrinos de catequismo y no del bautismo [...] a quienes advertí la obligación que tenían de instruir en la doctrina christiana a el antes bautizado, pero no les advertí parentesco espiritual alguno porque es probable no contraer alguno ${ }^{66}$

64. Alfani, 2009: 42-43. El Concilio de Trento limitó y redujo los parentescos espirituales creados en el bautismo que, con anterioridad, incluía a múltiples padrinos y a los hijos de estos.

65. CHACÓN JimÉnEZ, 1988: 49. Las obras que analizan la red de parentelas suelen limitarse a incluir solo el padrinazgo como único elemento de creación de parentesco espiritual.

66. ACDLu, Libro II de Bautismos, Matrimonios y Defunciones de Santa María de San Lourenzo de Penamaior, 1674-1763. 
Se puede apuntar que la diferenciación se hizo porque se trataba de una parroquia regida por una orden religiosa, pues el clero regular mostró mayor disciplina en lo tocante al bautismo en general. Sin embargo, fray Marcos Hurtado no parece estar totalmente seguro de que los padrinos no hubiesen contraído parentesco con el bautizado, Manuel (1703), y dejó reflejada dicha duda en la última línea.

La asimilación ente ambas figuras no fue estática en el tiempo, sino que hasta inicios del siglo XVIII, la tendencia mayoritaria era que padrinos y bautizantes fuesen distintos. A mediados del siglo XVII, el 28,57\% de los bautizantes ejerció después de padrinos; a inicios del siglo XIX, eran el 52,13\%. Por un lado, puede interpretarse como ese intento que citábamos sobre conseguir la mayor red social posible, frente a la reducción de esta que llevaban implícitas las nuevas disposiciones tridentinas. Por otro lado, también se puede considerar que el cambio fue debido a la mayor obediencia a las prescripciones del bautismo de socorro, incluyendo la preferencia de que bautizante y padrino fuesen la misma persona, conforme avanzó el control y la capacidad de la Iglesia.

La jerarquía que estableció la Iglesia entre los bautizantes acabó afectando a los modelos de padrinazgo y a las personas escogidas para ello. La correspondencia entre bautizante y padrino y la preferencia por un varón para echar agua de socorro explica que el modelo individual masculino $(31,61 \%)$ tuviese el doble de incidencia que el femenino $(13,55 \%)$. Y, a su vez, fue la causa de la menor incidencia del modelo de pareja $(46,77 \%)$ y del fuerte impacto de la ausencia de padrinos (7,7\%). El contraste parte de la comparación con el resto de niños, puesto que el modelo de pareja fue el predominante en toda la diócesis lucense: la incidencia mínima de este modelo fue, a mediados del siglo XIX, cuando se situó en el 64,19\% de los bautismos ${ }^{67}$.

67. Rey CASTElaO, 2015: 85-98. Se observa el mismo predominio de este modelo en la zona occidental de Galicia. En algunas parroquias como Bastavales (A Coruña), el modelo de pareja estuvo hasta el siglo XIX por encima del 92\%. 
Tabla 3. Modelos de padrinazgo empleados para los bautizados de socorro

\begin{tabular}{|l|c|c|}
\hline & N. $^{{ }^{\circ}}$ & $\%$ \\
\hline Modelo de Pareja & 148 & 46,77 \\
\hline Modelo Individual Masculino & 92 & 31,61 \\
\hline Modelo Individual Femenino & 42 & 13,55 \\
\hline Sin padrinos & 24 & 7,74 \\
\hline Modelos múltiples & 1 & 0,32 \\
\hline
\end{tabular}

Fuente: Partidas bautismales de 36 parroquias lucenses.

El perfil de los padrinos de estos niños divergió ligeramente de la tendencia general como consecuencia de las prisas y de la asimilación entre bautizante y padrino que, en muchos casos, parece que eliminó la necesidad de escoger padrinos. Por ejemplo, la participación de las élites como padrinos fue reducida como consecuencia del propio contexto del parto, en el que las élites no estarían presentes y, mucho menos, efectuarían un bautismo de socorro.

Por su parte, la familia tuvo un papel más activo en los padrinazgos de estos niños, por la mayor probabilidad de que estuviesen presentes en el parto y, por ende, más posibilidades de echar agua de socorro. En total, el 18,21\% de los bautizantes de socorro eran familiares de la madre y el 11,68\% del padre; proporción importante que certifica la asistencia a la parturienta por parte de la familia. La menor participación de la familia paterna frente a la materna, a pesar de ser en el hogar del marido donde se daba a luz por ser un área de predominio de matrimonios patrilocales, se explica con base en dos factores. Por un lado, la propia madre trataría de rodearse de su propia familia, al menos en el primer parto. Además, estadísticamente era más probable que esta conservase a su madre que a su suegra, dado que la edad de matrimonio de la mujer era inferior a la del hombre ${ }^{68}$. Por otro lado, hay que valorar el impacto de la ilegitimidad, cuyo auge comenzó en el momento máximo de los bautismos de socorro: a inicios del siglo XIX las proporciones de ilegítimos

68. FERnÁNDEZ CoRTIZO, 2010: 40. De los casados en el período de 1720-35, el 22,8\% eran hombres que tenían viva a su madre al momento del matrimonio frente al $28,7 \%$ de mujeres. Para el período de 1770-85, ambas cifras se elevaron, pero se mantuvo una diferencia porcentual a favor de las mujeres. 
alcanzan en ciertas parroquias el 20\%. Estos niños nacieron sin el reconocimiento paterno y, por tanto, sin la asistencia de esa rama familiar. A ello se suma que nacían en un entorno menos propicio, especialmente cuando se buscaba la ocultación, lo que provocaba un mayor riesgo para el bautizado y, por ende, de bautismos de socorro ${ }^{69}$.

\section{Conclusión}

En definitiva, la Iglesia consiguió apartar temporalmente a la mujer de cometidos con relevancia y reconocimiento social como podía ser el bautismo de socorro. Pese a ello, estas volvieron a desempeñar esas labores al compás de la privatización del entorno familiar y la consideración del parto como un espacio reservado para el pudor femenino.

En un espacio eminentemente rural como la diócesis de Lugo, las diferencias entre el entorno rural y urbano fueron evidentes. Así, los profesionales sanitarios estuvieron más presentes en las villas y ciudades que en las aldeas, con la consecuente mejor atención de las residentes en las primeras y una mayor posibilidad de que estos administrasen un bautismo de socorro. Sin embargo, la tendencia de dichos profesionales fue desvincularse del posterior padrinazgo y permitir que la estructura social siguiese los cauces iniciales, como si no se hubiese administrado agua de socorro.

Por el contrario, la actitud del resto de la población si favoreció la asimilación entre padrino y bautizante; aunque desconocemos si la presencia de estos en el parto, con la consecuente cristianización, estaba causada por haber sido elegidos previamente como padrinos. Independientemente de ello, la jerarquía establecida por la Iglesia repercutió directamente en las redes sociales creadas. Al predominar los hombres como bautizantes, el padrinazgo posterior acostumbró a recaer en ellos, especialmente en su versión individual que duplicó a la femenina. Aunque los padrinos hubiesen sido elegidos con

69. Rey CAStelao y BARReiro Mallón, 2014: 217. El traslado de las mujeres para dar a luz a hijos ilegítimos fue un factor importante. En la ciudad de Santiago, las foráneas representaron el 37,7\% de las madres. GONZÁLEZ LÓPEZ, II (2016): 83-84. En las áreas rurales, el impacto por parroquias parece ser menor, pero muestra la extensión de ese comportamiento. En las parroquias vitícolas del sur de la provincia de Lugo representaron el $17 \%$. 
anterioridad, la necesidad de un bautismo de socorro afectó a los modelos empleados y, por ende, a las personas a las que vinculó espiritualmente. El fuerte impacto de los modelos individuales entre estos niños así lo certifica, pues superan holgadamente las cifras de este modelo en su período de mayor auge.

En suma, en el rol de cada sexo en el bautismo de socorro y en el padrinazgo derivado se puede percibir el reflejo de la estructura social y los ámbitos permitidos a cada uno. Mientras cristianar en una emergencia gozaba de valor e importancia ante la comunidad y las autoridades eclesiásticas, los hombres tuvieron un papel activo. Por el contrario, conforme se percibió como un acontecimiento impúdico y privado y se redujo el tiempo que se dejaba mediar hasta llevar al neonato a la iglesia, se dejó todo lo relativo al parto en manos de las mujeres. A ello también contribuyó la citada medicalización del parto, que acabó por sustituir a los hombres por expertos, ya fuesen por la vía profesional como los cirujanos o las comadronas, ya fuesen por la vía de la experiencia, como las vecinas.

De todo esto se infiere una progresiva adquisición en la población de la necesidad religiosa de bautizar a sus hijos y de no correr el riesgo de que falleciesen sin recibir el bautismo. Al abrigo de la construcción social de la infancia como etapa diferenciada, creció la atención a la protección de su alma, tanto en el plano terrenal como en el celestial.

\section{Bibliografía}

ALFANI, Guido, Fathers and godfathers: spiritual kinship in early-modern Italy, Aldershot, Ashgate, 2009.

ARENA, Francesca, «La medicalizzazione del parto: un proceso dell'età moderna? Genere e medicina trasaperi e poteri (XVII-XX secoli)», en Sonia García Galán, Silvia Medina Quintana y Carmen Suárez Suárez (eds.), Nacimientos bajo control: el parto en las edades Moderna y Contemporánea, Gijón , Trea, 2014: 77-92.

ARIĖs, Philippe, El niño y la vida familiar en el antiguo régimen, Madrid, Taurus, 1987.

BARRIO GOZAlO, Maximiliano, «El clero bajo sospecha a principios del siglo XVIII: El Informe de Macanaz y la respuesta de los obispos», Investigaciones históricas: Época moderna y contemporánea, 22 (2002): 47-62. Disponible en: 
https://dialnet.unirioja.es/servlet/articulo? codigo=2654852 [consultado en 12 de marzo de 2018].

BASILICO, Alessio, «'Guadagnar quell'anima': battesimi d'emergenza e tempi di attesa dalla nascita nella diocesi di Teramo (1600-1730)», Popolazione e storia, 11/1 (2010): 9-25. Disponible en: https://popolazioneestoria.it/article/view/ ps2010-1 [consultado en 16 de abril de 2018].

BOROBIO, Dionisio, «Bautismo durante la Edad Media», Salmanticensis, 43/1 (1996): 15-42.Disponible en: https://summa.upsa.es/viewer.vm?id=7550\&view=main\&lang=es [consultado en 21 de noviembre de 2019].

Boullón Agrelo, Ana Isabel, «'Farruco, Paco, Fran': datos históricos e evolución dos hipocorísticos en Galicia», Revista galega de filoloxía, 8 (2007): 11-56. Disponible en: https://dialnet.unirioja.es/servlet/articulo? codigo=2521794 [consultado en 21 de mayo de 2018].

Carmona GonZÁlez, Inmaculada y Saiz Puente, María Soledad, «El bautismo de urgencia, función tradicional de las matronas», Matronas profesión, 4 (2009): 14-19. Disponible en: https://dialnet.unirioja.es/servlet/articulo?codigo $=4418334$ [consultado en 17 de marzo de 2018].

CHACÓN JIMÉNEZ, Francisco, «Identidad y parentescos ficticios en la organización social castellana de los siglos XVI y XVII: el ejemplo de Murcia», en Augustin Redondo (ed.), Les parentés fictives en Espagne (XVIe-XVIIe siècles), París, Publications de la Sorbonne, 1988: 37-50.

DUBERT GARCÍA, Isidro, «Alma de curas y Cura de almas. Moral y comportamientos eclesiásticos en la Galicia interior durante el Antiguo Régimen (16001830)», en Marco Virgilio García Quintela (ed.), Las religiones en la historia de Galicia, A Coruña, Servicio de Publicaciones Universidade da Coruña, 1996: 379-412.

FERnÁndez Cortizo, Camilo, «Matrimonio y régimen dotal en la Galicia de transición al interior en el siglo XVIII», en Maria Marta Lobo de Araújo y Alexandra Esteves (eds.), Tomar estado: dotes e casamentos (séculos XVI-XIX), Braga, CITCEM, 2010: 33-55. Disponible en: http://www.usc.es/hmoderna/ publicacion/fcc5/ [consultado en 17 de marzo de 2018].

FINE, Agnès, «Le parrain, son filleul et l'au-delà», Études rurales, 105-106 (1987): 123-146. https://doi.org/10.3406/rural.1987.3185

FlORES DE LA FLOR, María Alejandra, «La problemática del bautismo del ser deforme (monstruo) durante la Edad Moderna», Hispania Sacra, LXVI/2 (2014): 169-194. https://doi.org/10.3989/hs.2014.088 
LÓPEz Gallo, Alonso, Constituciones Sinodales de Lugo hechas por el Ilustrísimo Señor Obispo don Alonso López Gallo, [Manuscrito], 1618.

García y García, Antonio (dir.), Synodicon hispanum, I: Galicia, Madrid, Biblioteca de Autores Cristianos, 1981.

GARCÍA y GARCía, Antonio (dir.), Synodicon hispanum, III: Astorga, León y Oviedo, Madrid, Biblioteca de Autores Cristianos, 1984.

GONZÁlEZ LÓPEZ, Tamara, «Marcados dende o berce: ilexítimos nas parroquias ribeirás do Miño medio», Alicerces. Revista de estudos do Miño medio, II (2016): 77-93.

GONZÁlEZ LOPO, Domingo L., «De bárbaros a devotos: la reforma tridentina en Galicia (1550-1750)», en Juan Bosco Amores Carredano (coord.), Religión, herejías y revueltas sociales en Europa y América: VII Jornadas de Estudios Históricos del Departamento de Historia Medieval, Moderna y de América, Bilbao, Universidad del País Vasco, 2008: 141-71.

González Reboredo, Xosé Manuel y Mariño Ferro, Xosé Ramón (eds.), Nacemento, casamento e morte en Galicia: resposta á enquisa do Ateneo de Madrid, (1901-1902), Santiago de Compostela, Consello da Cultura Galega, 1990.

Gourdon, Vincent, Georges, Céline y Labejof, Nicolas, «Londoiement en paroisse à Paris au XIXe siècle», Histoire urbaine, 10 (2004): 141-79. https:// doi.org/10.3917/rhu.010.0141

IGLESIA GONZÁleZ, Antonio de la, El idioma gallego: su antigüedad y vida. T. III, A Coruña, La Voz de Galicia, 1886.

Manrique de Lara, Francisco, Constituciones Sinodales del Obispado de Orense, Santiago de Compostela, Consello da Cultura Galega, 1994.

MARTínez RodRíGUEZ, Enrique, «La mortalidad infantil y juvenil en la Galicia urbana del Antiguo Régimen: Santiago de Compostela, 1731-1810», Obradoiro de Historia Moderna, 1 (1992): 45-78. Disponible en: http://www.usc.es/revistas/index.php/ohm/article/view/591 [consultado el 25 de febrero de 2018].

Medina, Antonio, Cartilla nueva, útil, y necesaria para instruirse las matronas, que vulgarmente se llaman comadres, en el oficio de partear mandada hacer por el Real Tribunal del Protho-Medicato, Madrid, Imp. Antonio Delgado, 1785. Disponible en: http://bdh-rd.bne.es/viewer.vm?id=0000175758\&page=1 [consultado el 18 de enero de 2019].

Minvielle, Stéphane, Dans l'intimité des familles bordelaises: les élites et leurs comportements au XVIIIe siècle, Bordeaux, Éd. Sudouest, 2009. 
Moratinos y SAntos, Matías, Constituciones Synodales del Obispado de Lugo. Compiladas, hechas y promulgadas por el Ilmo. Sr. D. Matías de Moratinos... en la synodo que se celebró en su Iglesia Catedral de la dicha Ciudad en el mes de Febrero de mil y seiscientos y sesenta y nueve años, Madrid, Ioseph Fernández de Buendía, 1675.

Morte ACín, Ana, «La fama de santidad femenina en el convento de la Encarnación de Zaragoza», en Eliseo Serrano Martín y Jesús Gascón Pérez (eds.), Poder, sociedad, religión y tolerancia en el mundo hispánico,de Fernando el Católico al siglo XVIII, Zaragoza, Instituto Fernando Católico, 2018: 963-976. Disponible en: https://ifc.dpz.es/recursos/publicaciones/36/99/_ebook.pdf [consultado el 18 de enero de 2019].

PABlo V, Papa, Ritual Romanum, Roma, Cámara Apostólica, 1614.

PICCO, Dominique, «Les ondoyées parmi les demoiselles de Saint-Cyr: (XVIIXVIII siècles)», en Guido Alfani, Philippe Castagnetti y Vincent Gourdon (eds.), Baptiser: pratique sacramentelle, pratique sociale (XVIe-XXe siècle), Saint-Étienne, Université de Saint-Étienne, 2009: 203-222.

REY CASTELAO, Ofelia, «La diócesis de Lugo en la época moderna», en José García Oro (ed.), Historia de las diócesis españolas. Iglesias de Lugo, Mondoñedo-Ferrol y Orense, Madrid, Biblioteca de Autores Cristianos, 2002: 95-166.

ReY CASTELAO, Ofelia, "Parrains et marraines en Galice aux XVIe-XIXe siècles: le diocèse de Saint-Jacques-de-Compostelle», en Guido Alfani, Vincent Gourdon y Isabelle Robin (ed.), Le parrainage en Europe et en Amérique. Pratiques de longue durée, XVIe-XXIe siècle, Bruselas, Peter Lang, 2015: 69-98.

Rey CASTElaO, Ofelia y BARREIRO MALlón, Baudilio, «Apadrinar a un pobre en la diócesis de Santiago de Compostela, siglos XVII-XIX», en María José Pérez Álvarez y Maria Marta Lobo de Araújo (eds.), La respuesta social a la pobreza en la Península Ibérica durante la Edad Moderna, León, Servicio de Publicaciones de la Universidad de León, 2014: 209-238.

Rey Castelao, Ofelia y Rial García, Serrana, Historia das mulleres en Galicia. Idade Moderna, Santiago de Compostela, Xunta de Galicia, Nigratrea, 2010. Rial García, Serrana, O traballo das mulleres na Galicia rural do Antigo Réxime, Santiago de Compostela, Concello de Santiago de Compostela/Universidade de Santiago de Compostela, 2009.

Rodríguez LuSitANO, Fray Manuel, Summa de casos de consciencia con advertencias muy provechosas para Confessores con una Orden Judicial a la postre en la 
que se resuelve lo más ordinario de todas las materias morales, Barcelona, Imp. Sebastián de Cornellas, 1596.

SAAVEdRA FernÁndez, Pegerto, «Datos para un estudio comarcal da mortandade de 'párvulos' en Galicia (fins do XVII - mediados do XIX)», Obradoiro de Historia Moderna, 1 (1992): 79-95. http://www.usc.es/revistas/index.php/ ohm/article/view/592 [consultado el 14 de abril de 2018].

SAAVEDRA FERnÁNDEZ, Pegerto, «La economía vitícola en la Galicia del Antiguo Régimen», Agricultura y sociedad, 62 (1992): 111-166. Disponible en: https:// www.mapa.gob.es/app/publicaciones/art_datos.asp?articuloid=1647\&codrevista=AyS [consultado el 31 de mayo de 2018].

SAAVEDRA Fernández, Pegerto, La vida cotidiana en la Galicia del Antiguo Régimen, Barcelona, Crítica, 1994.

SAGE-PRANCHÈRE, Nathalie, Mettreau monde: sages-femmes et accouchées en Corrèze au XIXe siècle, Tulle, Archives départementales de la Corrèze, 2007.

SÁNCHEZ DIEGO, Héctor Fernando, «Bautismo y padrinazgo en las sinodales castellanas antes y después de Trento: norma vs. realidad», en Ofelia Rey Castelao, Rubén Castro Redondo y Camilo Fernández Cortizo (eds.), La vida inquieta. Conflictos sociales en la Edad Moderna, Santiago de Compostela, Universidade de Santiago de Compostela, 2018: 337-354.

Sobrado Correa, Hortensio, Las tierras de Lugo en la Edad Moderna: economía campesina, familia y herencia, 1550-1860, A Coruña, Fundación Pedro Barrié de la Maza, 2001.

SUÁREZ ÁlVAREZ, Patricia, «El arte de partear: parteras y parturientas a lo largo de la Edad Media», en Sonia García Galán, Silvia Medina Quintana y Carmen Suárez Suárez (eds.), Nacimientos bajo control: el parto en las edades Moderna y Contemporánea, Gijón ,Trea, 2014: 39-49.

TASSIN, Guy, Avoir des enfants au XVIIIe siècle: natalité, fécondité et mentalités à Haveluy, París, L'Harmattan, 1998.

Vela, Diego, Constituciones sinodales del Obispado de Lugo, Madrid, Vda. Alonso Martín de Balboa, 1632.

VEGA, Fray Alonso, Espejo de curas, utilissimo para todo genero de Ecclesiasticos, $y$ principalmente para aquellos que tienen cargo de animas, por comprehenderse en el todo lo que les es necessario para cumplir con la obligacion que tienen, Madrid, Pedro Madrigal, 1602. 